\title{
Role of Chlamydia pneumoniae and Mycoplasma pneumoniae as Causative Agents of Community-Acquired Pneumonia in Hospitalised Children and Adolescents
}

Published online: 11 November 2003

(C) Springer-Verlag 2003

\begin{abstract}
The aim of the study presented here was to determine the prevalence of Chlamydia pneumoniae versus Mycoplasma pneumoniae infections in paediatric patients with community-acquired pneumonia. A total of 50 patients (mean age, 5.5 years; median, 3.9 years) with community-acquired pneumonia were enrolled. Four patients were found to have Chlamydia pneumoniae infection ( 1 culture positive, 1 PCR positive and 2 serology positive) and 16 patients had Mycoplasma pneumoniae infection (2 PCR positive, 4 PCR and serology positive, 10 serology positive), including three patients with coinfection. The rates of Mycoplasma pneumoniae infection were $22 \%, 35 \%$ and $40 \%$ in children aged 1-3, >3-7 and >7 years, respectively. Acute Chlamydia pneumoniae infection was substantially less common than Mycoplasma pneumoniae infection in our study cohort.
\end{abstract}

\section{Introduction}

Little is known about the frequency of communityacquired pneumonia (CAP) caused by Chlamydia pneumoniae in paediatric patients in Europe, and the results published so far are conflicting. Prevalence rates of between $6 \%$ and $23 \%$ have been reported so far for Chlamydia pneumoniae found in the nasopharynx of healthy children using the polymerase chain reaction

This work was presented in part at the 40th Interscience Conference on Antimicrobial Agents and Chemotherapy (ICAAC), Toronto, Canada, 17-20 September 2000 (Poster \#588)

G. Baer · G. Engelcke · U. B. Schaad · U. Heininger $(\square)$

University Children's Hospital,

P.O. Box, 4005 Basel, Switzerland

e-mail: Ulrich.Heininger@unibas.ch

Tel.: +41-61-685-6528

Fax: +41-61-685-6012

M. Abele-Horn

Department of Hygiene and Microbiology,

University of Würzburg,

Josef-Schneider-Strasse 2, 97080 Würzburg, Germany
(PCR) $[1,2]$. Furthermore, in studies using combinations of PCR, culture and serology, Chlamydia pneumoniae has been identified as the presumptive causative agent of CAP in children to various degrees $[3,4,5,6,7]$.

The goal of the present study was to estimate the prevalence of Chlamydia pneumoniae infections in comparison with Mycoplasma pneumoniae infections in paediatric patients with CAP admitted to the University Children's Hospital, which provides basic paediatric care for the region of Basel, Switzerland.

\section{Patients and Methods}

The study was performed from March 1999 to February 2000, and all patients aged 1-18 years who were hospitalised with a diagnosis of radiographically proven CAP were eligible for participation. To avoid interference of maternally derived IgG antibodies with the serological diagnosis, infants were not enrolled. Subjects were also excluded for the following reasons: known immunodeficiency, treatment with immunoglobulins during the previous 3 months, or chronic underlying disease. The diagnosis of pneumonia required characteristic clinical findings as proposed by the World Health Organization [8], i.e. tachypnoea, respiratory distress, cyanosis, feeding difficulty, absence of wheezing, and radiological confirmation. Chest radiographs were assessed by the consultant radiologist who was unaware of the microbiological diagnosis. The study protocol was approved by the ethical commission of the University of Basel Medical Faculty.

Nasopharyngeal aspirates and oropharyngeal specimens were obtained for PCR using Dacron swabs from each patient on admission, and one further oropharyngeal specimen was obtained for culture (Chlamydia pneumoniae). Nasopharyngeal aspirates and oropharyngeal specimens were placed into transport medium $(0.9 \%$ sodium-chloride solution) and stored at $4^{\circ} \mathrm{C}$ until PCR was performed (within $48 \mathrm{~h}$ ). DNA was extracted and purified by proteinase $\mathrm{K}$ digestion followed by phenol-chloroform extraction and ethanol precipitation. For Chlamydia pneumoniae, a seminested PCR was performed using the primer pair HL/HR-1 and HM/HR-1 as described previously [9]. PCR of Mycoplasma pneumoniae was performed using the method described by Ieven et al. [10] with the primer pair MP P1-1 and MP P1-2. In-house validation tests have been performed for both PCR methods.

Cycloheximide-treated HEp 2 cells were used for culture of Chlamydia pneumoniae. Confirmation of suspicious cells was performed using fluorescent antibody staining with an in-house Chlamydia pneumoniae-specific monoclonal antibody [11]. 
Acute (on admission) and convalescent (4-6 weeks postadmission) serum samples were collected. Antibody titres (IgG, $\operatorname{IgM}$ and $\operatorname{Ig} \mathrm{A}$ ) for Chlamydia pneumoniae were measured using a microimmunofluorescence assay that includes positive and negative controls (Serofia; Savyon Diagnostics, Switzerland). For Mycoplasma pneumoniae, a semiquantitative enzyme-linked immunosorbent assay (SeroMP; Savyon Diagnostics) was performed (IgG and IgM). Antibody values were determined using the reference line method, which allows the calculation of elevations in antibody levels. The antigen used was the P1 membrane protein. Serum samples that were positive for IgM but negative for $\mathrm{IgG}$ by enzyme-linked immunosorbent assay were also analyzed using the particle agglutination test and immunoblotting (Virotech, Germany).

Statistical analysis was performed using SPSS version 10.0 for Windows. Independent proportions were compared using Fisher's exact test or the Mantel-Haenszel chi-square analysis, as appropriate. A $P$ level $<0.05$ was considered significant.

\section{Results and Discussion}

During the 12-month study period, 64 patients hospitalised with CAP were eligible for study participation and the parents of 50 of these patients provided informed consent for them to participate. Patients were aged 1.215.3 years (mean, 5.5 years; median, 3.9 years) and 29 were female. Nasopharyngeal aspirates and oropharyngeal specimens were available from all study participants and acute and convalescent serum specimens were obtained from 49 and 46 subjects, respectively. Five patients had received antibiotic treatment for at least $48 \mathrm{~h}$ before hospitalisation. Mean temperature on admission was $39.2^{\circ} \mathrm{C}$ (range, $36.4-40.2^{\circ} \mathrm{C}$ ). Mean peripheral leucocyte count on admission was $18.0 \times 10^{9} / 1$ (median, $16.7 \times 10^{9} / 1$; range, $\left.4.6-44 \times 10^{9} / 1\right)$ and the mean C-reactive protein level was $140 \mathrm{mg} / \mathrm{l}$ (median, $124 \mathrm{mg} / \mathrm{l}$; range, 3$567 \mathrm{mg} / \mathrm{l}$ ). One of 40 blood cultures was positive and grew Streptococcus pneumoniae.

Overall, four patients were found to have Chlamydia pneumoniae infection (Table 1). Interestingly, three of the four patients with Chlamydia pneumoniae infection also had signs of concomitant Mycoplasma pneumoniae infection. In addition, three study subjects (aged 3.6, 11.1 and 12.4 years) had serological evidence of past Chlamydia pneumoniae infection. Three of the four patients with acute Chlamydia pneumoniae infection, including two with Chlamydia pneumoniae and Mycoplasma pneumoniae coinfection, showed lobar consolidation involving several adjacent segments. Their Creactive protein values on admission were $152 \mathrm{mg} / \mathrm{ml}$, $139 \mathrm{mg} / \mathrm{ml}$ and $258 \mathrm{mg} / \mathrm{ml}$. Of those three patients, two (both with Chlamydia pneumoniae and Mycoplasma pneumoniae coinfection) had pneumonia with effusion. One patient with Chlamydia pneumoniae and Mycoplasma pneumoniae coinfection had an interstitial pneumonia and a C-reactive protein value of $42 \mathrm{mg} / \mathrm{ml}$.

Overall, 16 patients, including three with concomitant Chlamydia pneumoniae infection, were diagnosed as having acute Mycoplasma pneumoniae infections. The incidence of Mycoplasma pneumoniae as the cause of CAP increased according to the age of the patients. Thirteen cases were diagnosed during the cold season (October-March) without any apparent clusters. Using enzyme-linked immunoassay, 17 patients were found to have signs of acute Mycoplasma pneumoniae infection. In eight of these subjects, the diagnosis relied on the presence of IgM antibodies only. Confirmatory particle agglutination test and immunoblot assay could be performed in seven cases; all samples tested positive with the particle agglutination test $(\geq 1: 40)$ and four were also confirmed by immunoblot. This decreases the total number of serologically confirmed cases of acute $\mathrm{Myco}$ plasma pneumoniae infection to 14 (Table 2). All patients recovered without significant sequelae, including a 14month-old girl with Mycoplasma pneumoniae infection who required 2 days of intensive care treatment for imminent respiratory failure.

Radiographic patterns of pneumonia did not correlate with aetiological diagnosis nor did the clinical characteristics, such as maximum body temperature, C-reactive protein values and leucocyte counts (data not shown).

In this study of 50 children and adolescents with CAP examined for signs of Chlamydia pneumoniae and Mycoplasma pneumoniae infection, we found Mycoplasma pneumoniae infection to be frequent $(32 \%)$ and its relative frequency tended to increase according to age. PCR and serology findings were concordant in $25 \%$ of cases and discordant in 75\%; PCR missed 10 of the 16

Table 1 Detection of Chlamydia pneumoniae and Mycoplasma pneumoniae in children and adolescents with CAP according to patient age

\begin{tabular}{|c|c|c|c|c|c|c|c|c|}
\hline \multirow[t]{2}{*}{ Age in year } & \multicolumn{4}{|c|}{ No. with $C$. pneumoniae ${ }^{\text {a }}$} & \multicolumn{4}{|c|}{ No. with $M$. pneumoniae ${ }^{b}$} \\
\hline & $\begin{array}{l}\mathrm{PCR}+ \\
(\text { Sero/cult }-)\end{array}$ & $\begin{array}{l}\text { Sero + } \\
(\text { PCR/cult -) }\end{array}$ & $\begin{array}{l}\text { Cult }+ \\
(\text { Sero/PCR -) }\end{array}$ & Any + & $\begin{array}{l}\text { PCR + } \\
(\text { Sero -) }\end{array}$ & $\begin{array}{l}\text { PCR + } \\
(\text { Sero +) }\end{array}$ & $\begin{array}{l}\text { Sero + } \\
(\text { PCR -) }\end{array}$ & Any + \\
\hline $1-3(n=18)$ & 1 & 1 & - & 2 & 2 & 1 & 1 & 4 \\
\hline$>3-7(n=17)$ & - & - & 1 & 1 & - & 1 & 5 & 6 \\
\hline$>7-16(n=15)$ & - & 1 & - & 1 & - & 2 & 4 & 6 \\
\hline Total $(n=50)$ & 1 & 2 & 1 & 4 & 2 & 4 & 10 & 16 \\
\hline
\end{tabular}

PCR, polymerase chain reaction; Sero, serology; Cult, culture

${ }^{a}$ Acute $C$. pneumoniae infection: positive culture or PCR or specific serological criteria, i.e. a single positive $\operatorname{IgM}(\geq 1: 20)$, IgA $(\geq 1: 20)$ or $\operatorname{IgG}(\geq 1: 512)$ titre or a $\geq 4$-fold IgG titre rise in paired serum specimens [14]

${ }^{\mathrm{b}}$ Acute M. pneumoniae infection: positive PCR (NP or OP) or positive IgM antibodies ( $\left.\geq 10 \mathrm{U} / \mathrm{ml}\right)$ in acute and/or convalescent serum specimens or a significant IgG antibody increase ( $\geq 4$-fold) in paired serum specimens 
Table 2 Antibody values (IgM/IgG) against Mycoplasma pneumoniae detected in acute and convalescent serum specimens of 50 paediatric patients with community-acquired pneumonia

\begin{tabular}{|c|c|c|c|}
\hline \multicolumn{2}{|l|}{ Antibody values ${ }^{\mathrm{a}}$} & \multirow{2}{*}{$\begin{array}{l}\text { No. of } \\
\text { patients }\end{array}$} & \multirow[t]{2}{*}{ Diagnosis $^{\mathrm{b}}$} \\
\hline Acute specimen & $\begin{array}{l}\text { Convalescent } \\
\text { specimen }\end{array}$ & & \\
\hline $\begin{array}{l}\text { IgM pos/IgG pos } \\
21 / 29 \\
40 / 12 \\
139 / 24 \\
48 / 37\end{array}$ & $\begin{array}{l}\text { IgM pos/IgG pos } \\
30 / 32 \\
37 / 10 \\
93 / 54 \\
61 / 42\end{array}$ & 4 & acute infection \\
\hline $\begin{array}{l}\text { IgM pos/IgG neg } \\
32 /- \\
37 /- \\
42 /- \\
13 /-\end{array}$ & $\begin{array}{l}\text { IgM pos/IgG neg } \\
27 /- \\
111 /- \\
52 /- \\
11 /-\end{array}$ & 4 & acute infection \\
\hline $\begin{array}{l}\text { IgM pos/IgG neg } \\
106 /- \\
94 /- \\
122 /- \\
117 /-\end{array}$ & $\begin{array}{l}\text { IgM pos/IgG pos } \\
83 / 42 \\
126 / 28 \\
114 / 38 \\
110 / 26\end{array}$ & 4 & acute infection \\
\hline $\begin{array}{l}\operatorname{IgM} \text { pos/IgG neg } \\
\text { 20/- }\end{array}$ & n.a. & 1 & acute infection \\
\hline$\underset{-/-}{\operatorname{IgM} \text { neg/IgG neg }}$ & $\begin{array}{l}\text { IgM pos/IgG neg } \\
\text { 13/- }\end{array}$ & 1 & acute infection \\
\hline $\begin{array}{l}\operatorname{IgM} \text { neg/IgG pos } \\
9 / 22 \\
-/ 40\end{array}$ & $\begin{array}{l}\text { IgM neg/IgG pos } \\
7 / 22 \\
-/ 28\end{array}$ & 2 & previous infection \\
\hline IgM neg/IgG neg & IgM neg/IgG neg & 33 & no infection \\
\hline
\end{tabular}

pos, positive; neg, negative; n.a., not available

${ }^{a}$ Antibody levels determined by enzyme-linked immunosorbent assay in binding units/ml and confirmed by particle agglutination test and immunoblot

${ }^{b}$ Acute infection: see Table 1; Previous infection: positive IgG/ negative IgM, no significant IgG antibody rise and negative PCR

total cases. Similarly, Waris et al. [12] were unable to demonstrate the presence of Mycoplasma pneumoniae by PCR in 10 of 20 children with serologically confirmed Mycoplasma pneumonia. Interestingly, only patients with negative $\operatorname{IgG}$ antibodies in the acute phase had a positive PCR result. In accordance with this observation, three of our four PCR-positive patients were positive for IgM but negative for IgG antibodies against Mycoplasma pneumoniae in their acute serum specimens. This observation suggests that Mycoplasma pneumoniae organisms may be harboured in the upper respiratory tract preferentially during the very early phase of infection.

It has been shown previously that a subset of patients with pneumonia and a corresponding positive culture or PCR result for Mycoplasma pneumoniae lack an antibody response to the organism [3]. The reasons for this are unknown. It is notable that both of our patients who were positive for Mycoplasma pneumoniae by PCR but lacking an antibody response were rather young (2.8 and 1.9 years). This suggests that the serological antibody response to Mycoplasma pneumoniae may mature with age.

In contrast to Mycoplasma pneumoniae, the rate of infection with Chlamydia pneumoniae was low in our study cohort (8\%). Moreover, two of the four cases were diagnosed based on demonstration of the organism in the upper respiratory tract without a concomitant antibody response in acute or convalescent serum specimens. This raises doubts about the quality of the PCR technique we used [13] and/or the aetiological role of Chlamydia pneumoniae in two of our cases, decreasing the rate of Chlamydia pneumoniae infection to $4 \%$. Similarly, in a previous study conducted in Germany, a rate of $5.6 \%$ was found for Chlamydia pneumoniae infection [2]. In contrast, several other studies identified Chlamydia pneumoniae as the cause of CAP at a higher rate, i.e. in $15-30 \%$ of children $[3,5,6,7]$. The significant differences among the relative frequencies of Mycoplasma pneumoniae and Chlamydia pneumoniae in association with CAP from study to study may be attributable to variable age groups, the kinds of diagnostic procedures used and the presence or absence of local outbreaks in the respective communities during the investigation period [2]. No such outbreak occurred during the course of our study.

Interestingly, three of our four cases with demonstrable Chlamydia pneumoniae colonization and/or infection had evidence of simultaneous Mycoplasma pneumoniae coinfection. This observation has been described before $[3,4$, $6]$. It raises the question of whether one pathogen simply facilitates the penetration of the other or whether both organisms act independently to cause the respiratory tract infection.

No specific radiological feature or laboratory parameter was found that allowed us to distinguish patients with Mycoplasma pneumoniae or Chlamydia pneumoniae infection from those without a known cause for pneumonia, which is in accordance with previous studies $[4,6]$. This highlights the need for specific microbiological tests capable of identifying patients with Mycoplasma pneumoniae or Chlamydia pneumoniae infection who may benefit from specific antibiotic treatment.

Acknowledgements We are grateful to J. Glaus and G. Tusch, technicians at the University of Basel Children's Hospital Microbiological Laboratory, for performing serum antibody analyses and to S. Jenny, S. Balogh and C. Möller for performing PCR assays. Technical advice on PCR by R. Hertel is also acknowledged. We thank Dr. H. Matile, Hoffmann-La Roche, Basel, for performing cultures of Chlamydia pneumoniae.

\section{References}

1. Normann E, Gnarpe J, Gnarpe H, Wettergren B (1998) Chlamydia pneumoniae in children attending day-care centers in Gavle, Sweden. Pediatr Infect Dis J 17:474-478

2. Schmidt SM, Müller CE, Mahner B, Wiersbitzky SKW (2002) Prevalence, rate of persistence and respiratory tract symptoms of Chlamydia pneumoniae infection in 1211 kindergarten and school age children. Pediatr Infect Dis J 21:758-762

3. Block S, Hedrick J, Hammerschlag MR, Cassel GH, Craft JC (1995) Mycoplasma pneumoniae and Chlamydia pneumoniae in pediatric community-acquired pneumonia: comparative efficacy and safety of clarithromycin vs. erythromycin ethylsuccinate. Pediatr Infect Dis J 14:471-477 
4. Wubbel L, Muniz L, Ahmed A, Trujillo M, Carubelli C, McCoig C, Abramo T, Leinonen M, McCracken GH (1999) Etiology and treatment of community-acquired pneumonia in ambulatory children. Pediatr Infect Dis J 18:98-104

5. Harris JA, Kolokathis A, Campbell M, Cassell GH, Hammerschlag MR (1998) Safety and efficacy of azithromycin in the treatment of community-acquired pneumonia in children. Pediatr Infect Dis J 17:865-871

6. Principi N, Esposito S, Blasi F, Allegra L, and the Mowgli Study Group (2001) Role of Mycoplasma pneumoniae and Chlamydia pneumoniae in children with community-acquired lower respiratory tract infections. Clin Infect Dis 32:1281-1289

7. Normann E, Gnarpe J, Gnarpe H, Wettergren B (1998) Chlamydia pneumoniae in children with acute respiratory tract infections. Acta Paediatr 87:23-27

8. World Health Organisation (1994) Program for control of acute respiratory infections. WHO/ARI/94.33

9. Campbell LA, Perez Melgosa M, Hamilton DJ, Kuo CC, Grayston JT (1992) Detection of Chlamydia pneumoniae by polymerase chain reaction. J Clin Microbiol 30:434-439

10. Ieven M, Ursi D, Van Bever H, Quint W, Niesters HGM, Goossens H (1996) Detection of Mycoplasma pneumoniae by two polymerase chain reactions and role of $M$. pneumoniae in acute respiratory tract infections in pediatric patients. J Infect Dis 173:1445-1452

11. Roblin PM, Dumornay W, Hammerschlag MR (1992) Use of HEp-2 cells for improved isolation and passage of Chlamydia pneumoniae. J Clin Microbiol 30:1968-1971

12. Waris ME, Toikka P, Saarinen T, Nikkari S, Meurman O, Vainionpää R, Mertsola J, Ruuskanen O (1998) Diagnosis of Mycoplasma pneumoniae pneumonia in children. J Clin Microbiol 36:3155-3159

13. Apfalter P, Barousch W, Nehr M, Makristathis A, Willinger B, Rotter M, Hirschl AM (2003) Comparison of a new quantitative ompA-based real-time PCR TaqMan assay for detection of Chlamydia pneumoniae DNA in respiratory specimens with four conventional PCR assays. J Clin Microbiol 41:592-600

14. Grayston JT, Campbell LA, Kuo CC, Mordhorst CH, Saikku P, Thom DH, Wang SP (1990) A new respiratory tract pathogen: Chlamydia pneumoniae strain TWAR. J Infect Dis 161:618625 